\title{
Extraction of coconut oil with Lactobacillus plantarum 1041 IAM
}

\begin{abstract}
Extraction of coconut oil with a pure culture of Lactobacillus plantarum 1041 IAM was investigated. Grated coconut meat and water at 30,50 , and $70^{\circ} \mathrm{C}$ were mixed in various ratios $(1: 1,1: 2$, and 1:3) and allowed to settle for $2 i ̈ 6 \mathrm{~h}$. The most efficient coconut cream separation was obtained at the $1: 1$ ratio of grated coconut meat to water at $70^{\circ} \mathrm{C}$, followed by $6 \mathrm{~h}$ settling time. Fermentation was then conducted on coconut cream emulsion with the sample from $1: 1$ ratio, $70^{\circ} \mathrm{C}$, and 6-h settling time. Oil yield from the fermentation process with $5 \%$ inoculum of L. plantarum 1041 IAM after $10 \mathrm{~h}$ at $40^{\circ} \mathrm{C}$ was $95.06 \%$ Quality characteristics of the extracted oil were as follows: moisture content, $0.04 \%$; peroxide value, $5.8 \mathrm{meq}$ oxygen $/ \mathrm{kg}$; anisidine value, 2.10; free fatty acid, $2.45 \%$; iodine value, 4.9 ; and color, $0.6(\mathrm{Y}+5 \mathrm{R})$. Extraction of coconut oil from coconut meat with L. plantarum 1041 IAM was significantly improved in both oil yield and quality over the traditional wet process.
\end{abstract}

Keyword: Coconut cream; Coconut meat; Fermentation; Lactobacillus plantarum 1041 IAM; Oil yield; Quality characteristics 